\title{
The updating of clinical practice guidelines: insights from an international survey
}

\author{
Pablo Alonso-Coello ${ }^{1,2}$, Laura Martínez García ${ }^{1 *}$, José Miguel Carrasco ${ }^{3}$, Ivan Solà ${ }^{1}$ Safia Qureshi ${ }^{4}$ and \\ Jako S Burgers ${ }^{5}$, for the Updating Guidelines Working Group
}

\begin{abstract}
Background: Clinical practice guidelines (CPGs) have become increasingly popular, and the methodology to develop guidelines has evolved enormously. However, little attention has been given to the updating process, in contrast to the appraisal of the available literature. We conducted an international survey to identify current practices in CPG updating and explored the need to standardize and improve the methods.

Methods: We developed a questionnaire (28 items) based on a review of the existing literature about guideline updating and expert comments. We carried out the survey between March and July 2009, and it was sent by email to 106 institutions: 69 members of the Guidelines International Network who declared that they developed CPGs; 30 institutions included in the U.S. National Guideline Clearinghouse database that published more than 20 CPGs; and 7 institutions selected by an expert committee.
\end{abstract}

Results: Forty-four institutions answered the questionnaire (42\% response rate). In the final analysis, 39 completed questionnaires were included. Thirty-six institutions (92\%) reported that they update their guidelines. Thirty-one institutions (86\%) have a formal procedure for updating their guidelines, and 19 (53\%) have a formal procedure for deciding when a guideline becomes out of date. Institutions describe the process as moderately rigorous (36\%) or acknowledge that it could certainly be more rigorous (36\%). Twenty-two institutions (61\%) alert guideline users on their website when a guideline is older than three to five years or when there is a risk of being outdated. Twentyfive institutions (64\%) support the concept of "living guidelines," which are continuously monitored and updated. Eighteen institutions (46\%) have plans to design a protocol to improve their guideline-updating process, and 21 (54\%) are willing to share resources with other organizations.

Conclusions: Our study is the first to describe the process of updating CPGs among prominent guideline institutions across the world, providing a comprehensive picture of guideline updating. There is an urgent need to develop rigorous international standards for this process and to minimize duplication of effort internationally.

\section{Background}

Clinical practice guidelines (CPGs) have become increasingly popular over the last two decades. In parallel, the methodology to develop guidelines has evolved enormously [1,2]. Major attention has been given to the selection and appraisal of the available literature, becoming progressively more systematic and comprehensive. The harmonization of grading systems to classify the quality of the evidence and the strength of recommendations has been a hot issue in the guideline arena [3]. As a result,

\footnotetext{
* Correspondence: laura.martinez.garcia@cochrane.es

'Iberoamerican Cochrane Centre, Institute of Biomedical Research (IIB Sant

Pau), (C/Sant Antoni Maria Claret 171), Barcelona (08041), Spain

Full list of author information is available at the end of the article
}

the quality of guidelines has been improved in the last decade. Nevertheless, there is still important room for improvement [4].

In guideline programs, the updating of guidelines is often scheduled irregularly [5]. Although there is no fixed lifespan for a guideline, an update every three to five years is generally recommended [6,7]. However, information about the process and methods for updating used by guideline organizations is lacking. Only few published research studies are available on this topic [6-9]. Few organizations include chapters or information on guideline updating in their handbooks on guideline development $[1,2]$.

\section{Ciomed Central}


A significant step forward is the synthesis of available research on updating of CPGs included in the handbook of the Programme of Clinical Practice Guidelines in the Spanish National Health System. This programme is coordinated by GuíaSalud http://www.guiasalud.es, an organization created in 2002 to promote the development and use of evidence-based guidelines and other tools for improving quality of care in the Spanish Health System. Following these objectives, a common methodology for producing, implementing, and updating CPGs has been developed [10-12]. Within this context, we conducted an international survey with the aim of identifying current practices in guideline updating, exploring the need for standardization, and, ultimately, improving the guideline-updating process.

\section{Methods}

Design

We employed a cross-sectional design for this study.

\section{Study population}

Our study population included key informants and experts affiliated with organizations dedicated to CPG development.

\section{Study sample}

We selected participant institutions in spring 2009 using the following criteria: (a) members of the Guidelines International Network http://www.g-i-n.net/ that declared that they developed CPGs, (b) institutions included in the U.S. National Guideline Clearinghouse http://www.guideline.gov/ that had published more than 20 CPGs, and (c) institutions additionally selected by an expert committee based on relevance. The expert committee was composed of 12 health professionals and methodologists with experience in the field of guideline methodology and information specialists. We sent an email to each institution through the address identified via the internet. If the person receiving this email was not the person responsible for this matter, we requested that it be forwarded to whoever they considered appropriate within that institution to answer the survey.

\section{Intervention}

We designed a self-administered survey (see Additional File 1) based on a literature review about guideline updating (unpublished). For this review, we studied websites of institutions that had published methodological handbooks and searched for published studies in MEDLINE (via PubMed) until June 2008 using a combination of descriptors (Practice Guidelines as Topic; Clinical Practice Guidelines) and free text terms (clinical guideline, practice guideline, updat*, up to date).
The survey comprised 28 items grouped into four domains. The first domain included characteristics of the organization (five items), the second was dedicated to the process of guideline updating (16 items), the third was aimed at the way users are alerted about guideline updates (two items), and the last domain focused on the future perspective on guideline updating (five items). Nineteen items included a free text area in order to gather comments or additional information.

Specific software was used to design the survey and to collect the responses http://www.surveymonkey.com. The survey was pilot tested among five institutions (three national and two international). Their feedback was used to refine the survey for optimal understanding. Between March and July 2009, we sent the survey via email to persons of selected institutions. We sent three reminders at intervals of four weeks to those institutions that had not responded. Questionnaires with no response on more than $20 \%$ of the items were returned with the request to complete the questionnaire.

\section{Analysis}

Descriptive statistics were used to analyze the data. We calculated absolute frequencies and proportions for all items. We evaluated nonresponding institutions and compared their contact source (Guidelines International Network, National Guideline Clearinghouse, or expert committee), country, and number of CPGs produced with responding institutions using Fisher's exact test or Mann-Whitney U test (alpha was set at 0.05). We finally excluded from the analysis four items (B13-B16, Additional File 1), as they were deemed to be more related to guideline development. We assessed the guideline-updating process of responding institutions by comparing the number of years developing CPGs ( $\leq 10$ years of experience or $>10$ years of experience), contact source, and number of guidelines published per year using Fisher's exact test (alpha was set at 0.05). Data analysis was performed using SPSS statistical software, version 17.0 (SPSS Inc., Chicago, IL, USA). By consensus of the three first authors, we collected and provide the most relevant themes brought up by the responders in the free text area (responses to free text questions available from the authors on request).

Ethics approval was obtained from the hospital ethics committee (Clinical Research Ethics Committee, Hospital de la Santa Creu i Sant Pau, \#74/2010).

\section{Results}

\section{Characteristics of study sample}

One hundred and fourteen institutions met at least one of the inclusion criteria. We contacted 106 of these institutions by email. We received a reply from 44 
institutions (42\% response rate) after three reminders. In the final analysis, we included 39 questionnaires. Five questionnaires were excluded because more than $20 \%$ of the questions were not answered (Figure 1).

Characteristics of the responding institutions are presented in Table 1 . The vast majority reported that they update their guidelines $(\mathrm{n}=36,92 \%)$. Nonresponding and excluded institutions $(n=67)$ did not differ from the responding institutions with regard to their contact source (Guidelines International Network, National Guideline Clearinghouse, or expert committee; Fisher's exact test $p=.671$ ), country of origin (Fisher's exact test $p=.283)$, and the number of guidelines produced (Mann-Whitney $\mathrm{U}$ test $p=.07$ ).

\section{Characteristics of the guideline-updating process}

Sixteen institutions (44\%) reported that they check more than five guidelines for the need for annual updating, some institutions reported variable figures $(\mathrm{n}=10,28 \%)$, and the remaining $10(28 \%)$ reported that they check five or less per year (Table 2, Figure 2). Over $60 \%$ of the institutions reported a time frame for considering a guideline update between three to five years. Thirty-one institutions $(86 \%)$ indicated that they have a formal procedure

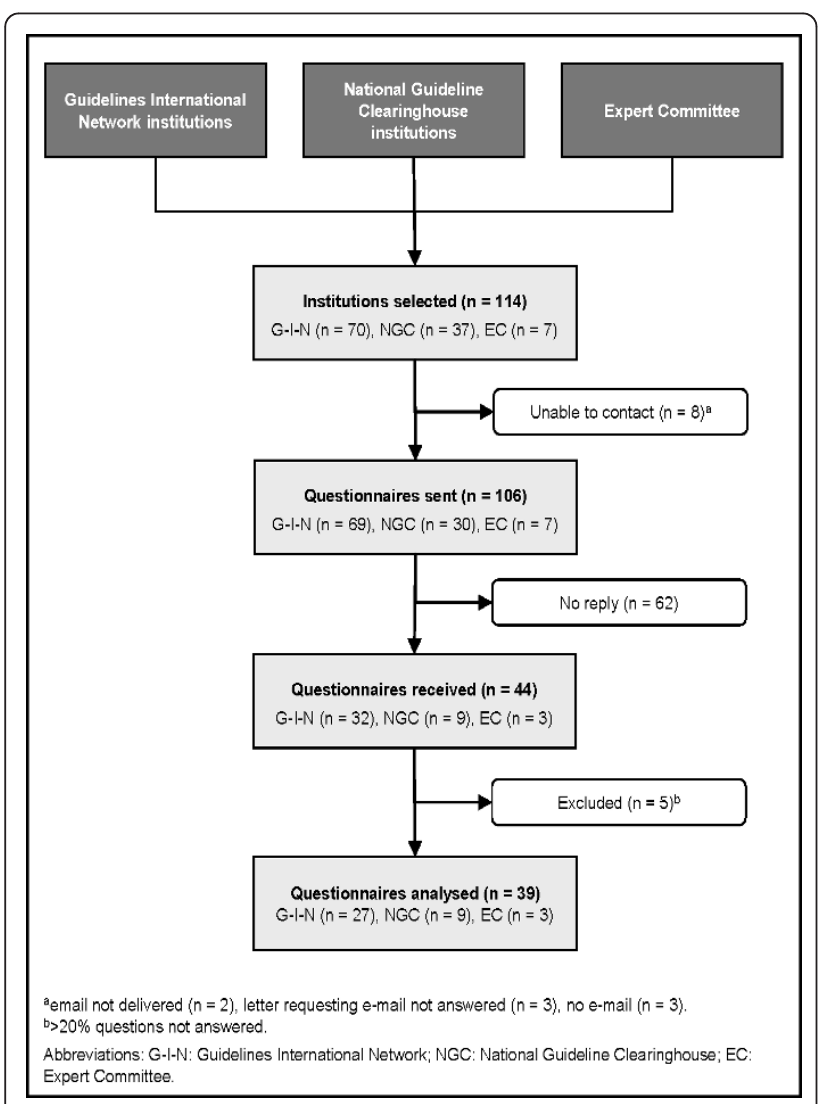

Figure 1 Participation diagram.
Table 1 Organization characteristics $(n=39)^{a}$

\begin{tabular}{|c|c|c|}
\hline & $\mathbf{n}$ & $(\%)$ \\
\hline \multicolumn{3}{|l|}{ Contact source } \\
\hline Guidelines International Network & 27 & $(69.2)$ \\
\hline U.S. National Guideline Clearinghouse & 9 & $(23.1)$ \\
\hline Expert committee & 3 & $(7.7)$ \\
\hline \multicolumn{3}{|l|}{ Continent } \\
\hline Europe & 17 & (43.6) \\
\hline North America & 15 & $(38.5)$ \\
\hline Oceania & 5 & $(12.8)$ \\
\hline South America & 1 & $(2.6)$ \\
\hline Asia & 1 & $(2.6)$ \\
\hline \multicolumn{3}{|l|}{ Type of organization } \\
\hline Scientific/professional society/association & 20 & $(51.3)$ \\
\hline Public institution & 14 & $(35.9)$ \\
\hline Other (Federal institute, nonprofit organization) & 5 & $(12.8)$ \\
\hline \multicolumn{3}{|l|}{ Number of years developing guidelines } \\
\hline$>10$ years & 24 & $(61.5)$ \\
\hline $6-10$ years & 12 & $(30.8)$ \\
\hline$\leq 5$ years & 3 & $(7.7)$ \\
\hline \multicolumn{3}{|l|}{ Number of guidelines published ${ }^{\mathbf{b}}$} \\
\hline$\leq 5$ per year & 24 & $(61.5)$ \\
\hline$>5$ per year & 14 & (35.9) \\
\hline \multicolumn{3}{|l|}{ Updating guidelines } \\
\hline Yes & 36 & $(92.3)$ \\
\hline No & 3 & $(7.7)$ \\
\hline
\end{tabular}

${ }^{\mathrm{a}}$ Analysis of included institutions; ${ }^{\mathrm{b}}$ One institution unknown.

for updating their guidelines, but only 19 (53\%) have a formal procedure for deciding when a guideline becomes out of date. Nine institutions (25\%) piloted the updating process to evaluate feasibility, inconveniences, or added value compared to other strategies.

Twenty-six institutions (72\%) described the process as moderately rigorous or acknowledged that it could certainly be more rigorous. Institutions that have been developing guidelines for more than 10 years are more likely to have a formal updating procedure (Fisher's exact test $p=$ .047 ) and a rigorous process for guideline updating (Fisher's exact test $p=.039$ ) than are institutions who have been developing guidelines for 10 or less years (Table 3 ). In general, the original guideline group or an expert committee is responsible for the decision about updating the guideline (Table 4, Figure 3). The original guideline authors are most often involved in the updating process $(\mathrm{n}=32$, $89 \%)$, followed by the institution's staff ( $\mathrm{n}=30,83 \%)$. In 13 institutions (36\%), patients are involved in the process.

Institutions tend to check and review different parts of the guideline when deciding about the need to update a guideline. Twenty-nine institutions (81\%) said they check all recommendations and the full guideline text. Less frequently, key questions and recommendations, supplementary annexes, and patient information are checked. 
Table 2 The guideline-updating process $(n=36)^{a}$

\begin{tabular}{|c|c|c|}
\hline & $\mathrm{n}$ & $(\%)$ \\
\hline \multicolumn{3}{|l|}{ Number of guidelines checked } \\
\hline$>5$ per year & 16 & $(44.4)$ \\
\hline Variable & 10 & $(27.8)$ \\
\hline 3-5 per year & 6 & $(16.7)$ \\
\hline$<3$ per year & 4 & $(11.1)$ \\
\hline \multicolumn{3}{|l|}{ Number of guidelines updated } \\
\hline Unknown & 14 & $(38.9)$ \\
\hline$\leq 5$ per year & 11 & (30.6) \\
\hline$>5$ per year & 7 & $(19.4)$ \\
\hline Variable & 4 & $(11.1)$ \\
\hline \multicolumn{3}{|l|}{ Time frame to check updating } \\
\hline $3-5$ years & 22 & $(61.1)$ \\
\hline$<3$ years & 11 & (30.6) \\
\hline Variable & 3 & $(8.3)$ \\
\hline \multicolumn{3}{|l|}{ Formal procedure to update guidelines } \\
\hline Yes & 31 & $(86.1)$ \\
\hline No & 5 & (13.9) \\
\hline \multicolumn{3}{|c|}{$\begin{array}{l}\text { Formal procedure to inform about guidelines being out } \\
\text { of date }\end{array}$} \\
\hline Yes & 19 & $(52.8)$ \\
\hline No & 17 & $(47.2)$ \\
\hline \multicolumn{3}{|c|}{$\begin{array}{l}\text { Formal method to decide update section or full } \\
\text { guideline }\end{array}$} \\
\hline No & 23 & $(63.9)$ \\
\hline Yes & 11 & (30.6) \\
\hline Unknown & 2 & $(5.6)$ \\
\hline \multicolumn{3}{|l|}{ Pilot testing of updating process } \\
\hline No & 24 & $(66.7)$ \\
\hline Yes & 9 & $(25.0)$ \\
\hline Unknown & 3 & $(8.3)$ \\
\hline \multicolumn{3}{|l|}{ Rigor of the updating process } \\
\hline Could certainly be more rigorous & 13 & $(36.1)$ \\
\hline Moderately rigorous & 13 & $(36.1)$ \\
\hline Very rigorous & 10 & $(27.8)$ \\
\hline
\end{tabular}

${ }^{a}$ Analysis of institutions updating guidelines.

- "We are currently in the process of reviewing the currency of all our guidelines, but following this we would expect to review less than 3 per year."

- "We are currently updating this procedure and it will be available in our updated handbook in late 2009."

- "We aim to update all topics at minimum every five years, using something of a rolling process to consider all topics, and also has a process for considering 'early' updates."

- "Through our experience of reviewing/updating guidelines over the past seven years, no guideline recommendations have been determined to be unsafe for practice due to new evidence. However, many recommendations and supports for implementation have been further supported with updated evidence."

Figure 2 Box of relevant comments about the characteristics of the guideline-updating process.
The institutions use several search strategies (Table 4, Figure 4). Twenty institutions (56\%) ran the original search strategies and did additional horizon scanning, 14 institutions (40\%) use more specific strategies than the original strategies, and seven (20\%) institutions run other searches. Twenty-two institutions (61\%) alert guideline users on their website when a guideline is older than three to five years or when there is a risk of being outdated.

\section{Future plans for updating guidelines}

Twenty-five institutions (64\%) supported the concept of "living guidelines" (Table 5, Figure 5), defined as guidelines that are continuously monitored and updated [13]. The majority of institutions, however, reported difficulties and inconvenience in putting this concept in practice. Almost half of the institutions reported that they have plans to improve their guideline-updating process ( $n=18,46 \%)$. More than half of the institutions are willing to share resources with other organizations ( $n=21,54 \%)$. However, only $20 \%$ of the organizations reported that they would rely on other guidelines when updating or developing a guideline.

\section{Discussion}

Our study is the first international survey about the process of updating CPGs among guideline institutions across the world. Although most institutions reported having a process for updating guidelines, the process is not standardized and could be more rigorous. Many guideline developers, including those with long-standing experience, reported that they have plans to improve this process. Others are waiting for more evidence before modifying their current system.

Surprisingly, half of the organizations do not have a formal process for deciding when a guideline becomes outdated. Guideline developers need to recognize this limitation when promoting guidelines as support tools for the practice of evidence-based medicine. Similarly, guideline users should be cautious when relying on guidelines of a certain age. This lack of rigor in methodology in general was recently found in a systematic review about the quality of guidelines in the last two decades $[4,14]$. On the other hand, most organizations in our survey showed awareness about using insufficient methods for updating guidelines and intended to improve their processes. Up to $72 \%$ think that their updating process is only moderately rigorous or could be more rigorous. This is an issue that guideline developers need to address. This finding is consistent with the fact that only $20 \%$ of organizations in our survey would rely on other guidelines when updating or developing a guideline. This is an unfortunate paradox given the actual scenario, where most institutions would like to be 
Table 3 The guideline-updating process by numbers of years developing guidelines $(n=36)^{a}$

\begin{tabular}{|c|c|c|c|c|c|c|c|}
\hline & \multicolumn{4}{|c|}{ Numbers of years developing guidelines } & \multirow{2}{*}{\multicolumn{2}{|c|}{ Total }} & \multirow[b]{3}{*}{$p^{\mathrm{b}}$} \\
\hline & \multicolumn{2}{|c|}{$\leq 10$ years } & \multicolumn{2}{|c|}{$>10$ years } & & & \\
\hline & $\mathbf{n}$ & (\%) & $\mathrm{n}$ & (\%) & $\mathrm{n}$ & $(\%)$ & \\
\hline \multicolumn{8}{|l|}{ Formal procedure to update guidelines } \\
\hline Yes & 9 & $(69.2)$ & 22 & $(95.7)$ & 31 & $(86.1)$ & .047 \\
\hline No & 4 & $(30.8)$ & 1 & $(4.3)$ & 5 & $(13.9)$ & \\
\hline \multicolumn{8}{|l|}{ Time frame to check updating } \\
\hline $3-5$ years & 7 & $(53.8)$ & 15 & $(65.2)$ & 22 & $(61.1)$ & .094 \\
\hline$<3$ years & 3 & $(23.1)$ & 8 & $(34.8)$ & 11 & $(30.6)$ & \\
\hline Varies & 3 & $(23.1)$ & - & & 3 & $(8.3)$ & \\
\hline \multicolumn{8}{|l|}{ Rigor of the updating process } \\
\hline Could certainly be more rigorous & 8 & $(61.5)$ & 5 & $(21.7)$ & 13 & $(36.1)$ & .039 \\
\hline Moderately rigorous & 4 & $(30.8)$ & 9 & $(39.1)$ & 13 & $(36.1)$ & \\
\hline Very rigorous & 1 & $(7.7)$ & 9 & $(39.1)$ & 10 & $(27.8)$ & \\
\hline
\end{tabular}

${ }^{\mathrm{a}}$ Analysis of institutions updating guidelines; ${ }^{\mathrm{b}}$ Fisher's exact test.

Table 4 Characteristics of the guideline-updating process $(n=36)^{a}$

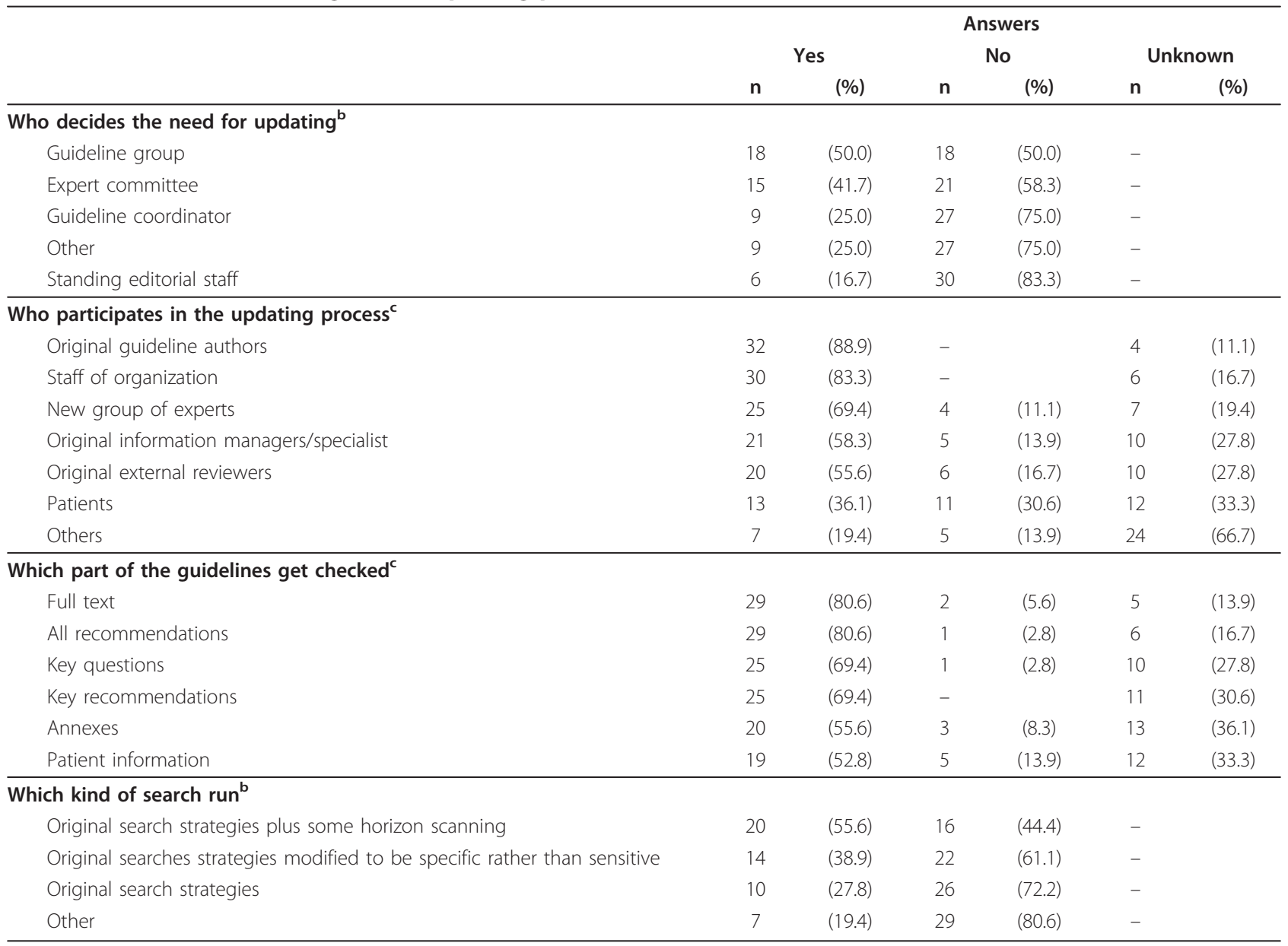

${ }^{\mathrm{a}}$ Analysis of institutions updating guidelines; ${ }^{\mathrm{b}}$ Closed-ended questions yes/no; ${ }^{\mathrm{c}}$ Aggregation responses yes/partially. 


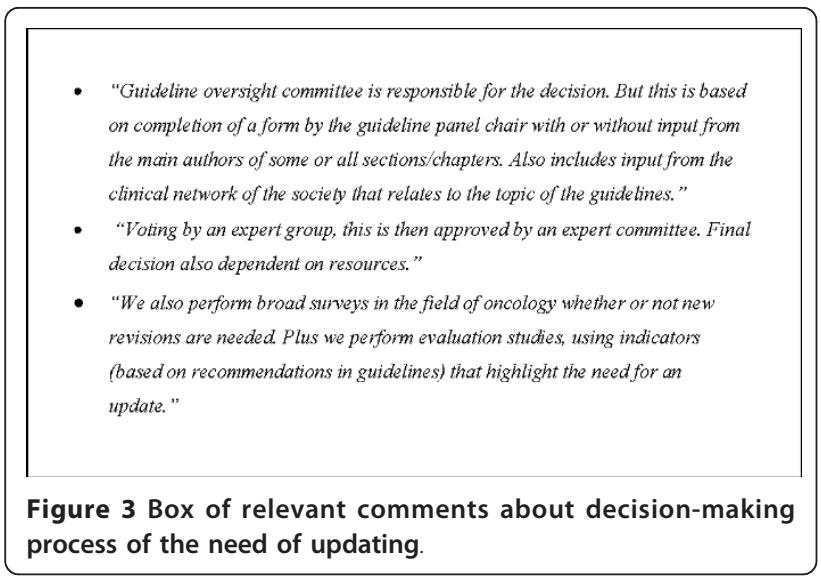

able to share the burden of the development process. There is a perceived need for international collaboration, but the product to be exchanged needs to be more mature.

The majority of institutions support the concept of living guidelines. However, this type of guideline development is regarded as very labour intensive and resources may be insufficient. This modality could make more sense in fast-changing fields such as AIDS, cardiovascular risk management, and breast cancer. Guidelines on other topics, such as venous ulcer or sinusitis, may need less frequent updating. Some responders emphasized that guideline updating should be tailored to the topic in order to optimize the efficient use of resources (Figure 5).

A noted limitation of frequent updating of guidelines is that notifications of each update could be burdensome for developers and users (Figure 5). Users' interests may vary for different kinds of updates, some being interested in any change made to the guideline, some just being concerned about major modifications. Ideally, web-based organizations could have personalized systems of alerts that could be tailored to each user group.

- "We may update the search strategy depending on how old it is, we always include a horizon scanning element."

- "We have two distinct types of updates, one that we call "Reaffirmation updating" which follows a limited, specific, protocol for the search; and the other that generally follows and updates the original searches but not infrequently may have modified a question or introduced a new question so that a full search must be done for that question."

Figure 4 Box of relevant comments about the characteristics of the search process.
Sufficient funding is important for appropriate guideline updating. Guideline organizations that are structurally embedded within the countries' healthcare system and funded by the government, such as the National Institute for Health and Clinical Excellence (NICE) and the Scottish Intercollegiate Guidelines Network (SIGN), have more rigorous updating procedures. In organizations with fewer resources, funding is only available for developing de novo guidelines. Research in the field of guideline updating is scarce. There is an urgent need for valid tools to estimate the rate of new relevant findings related to the topic of the guideline and for efficient search strategies to track new research evidence. In addition, more knowledge is needed about the best method to reach end users when guidelines are out of date and when guidelines are updated.

Our survey shows that institutions consider guideline updating to be time consuming and resource intensive. Despite the limitations described above, over half of the institutions surveyed are eager to share the burden and work with peer institutions. International collaboration could further help to avoid duplication of effort. Some institutions suggested that a forum to discuss and share updating experiences would be helpful (Figure 5). The Guidelines International Network could provide these facilities, in the same way that they support other groups active in guideline methodology.

Work is being duplicated around the world, with institutions failing to work jointly, consolidating networks around health topics or fields. Timidly but progressively, international collaboration on guideline development and updating for chronic obstructive pulmonary disease (COPD) has been initiated recently [15]. In the field of oncology, a European collaboration of guideline institutions (CoCanCPG) has been active [16]. To increase the efficient use of existing guidelines in guideline updating, the ADAPTE methodology could be helpful [17]. In addition, a standardized format for evidence tables and for grading the evidence could help with sharing evidence worldwide $[3,18]$. Finally, international databases of gaps in evidence could be developed, which could feed the agenda of healthcare researchers and reviewers, such as the Cochrane Collaboration.

This study has a few limitations. First, the response rate was rather low, despite sending three reminders. Nevertheless, our survey included the most prominent guideline organizations, like NICE, SIGN, the United States Preventive Services Task Force, and the New Zealand Guidelines Group (Additional File 2). We did not find essential differences between responding and nonresponding institutions. Second, bias cannot be excluded due to the nature of the survey being self-reported. Although we contacted a key informant from each institution, other responders from the same institutions 


\begin{tabular}{|c|c|c|c|c|c|c|}
\hline & \multicolumn{6}{|c|}{ Answers } \\
\hline & \multicolumn{2}{|c|}{ Yes } & \multicolumn{2}{|c|}{ No } & \multicolumn{2}{|c|}{ Not sure/unknown } \\
\hline & $\mathbf{n}$ & (\%) & $\mathbf{n}$ & (\%) & $\mathrm{N}$ & (\%) \\
\hline It is worth having living guidelines ${ }^{b}$ & 25 & $(64.1)$ & 6 & $(15.4)$ & 8 & $(20.5)$ \\
\hline Plans to set up a protocol to improve the updating process & 18 & $(46.2)$ & 10 & $(25.6)$ & 11 & $(28.2)$ \\
\hline Share resources with other organizations & 21 & $(53.8)$ & 1 & $(2.6)$ & 17 & $(43.6)$ \\
\hline \multicolumn{7}{|l|}{ Resources to share $(n=21)$} \\
\hline - References & 20 & $(95.2)$ & - & & 1 & $(4.8)$ \\
\hline - Evidence synthesis & 19 & $(90.5)$ & - & & 2 & $(9.5)$ \\
\hline - Key questions & 18 & $(85.7)$ & - & & 3 & $(14.3)$ \\
\hline - Search strategies & 18 & $(85.7)$ & - & & 3 & $(14.3)$ \\
\hline - Evidence tables & 18 & $(85.7)$ & 1 & $(4.8)$ & 2 & $(9.5)$ \\
\hline - Considered judgement forms ${ }^{c}$ & 14 & $(66.7)$ & - & & 7 & (33.3) \\
\hline
\end{tabular}

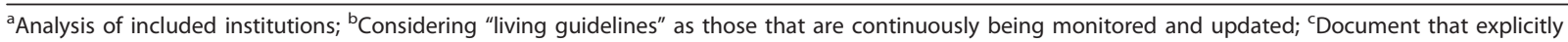
includes the factors taken into account when grading recommendations.

might have provided different answers. In some institutions, the person initially contacted referred us to another person more able to answer the questions, which increases the likelihood of appropriate answers.

\section{Conclusions}

Our study provides the first comprehensive picture of guideline updating around the world. This stage in guideline development has not benefited from the same rigor of methodological development that has been applied to the initial development of a guideline. Our study shows that it is an area that needs increasing attention. Our main findings include the urgent need to develop a rigorous standard for this process, initially by funding research into how to optimize the process, share the burden, and minimize duplication of effort internationally. We believe that these changes will improve the quality and impact of guidelines and, ultimately, patient care.

- "We've tried to implement a 'iving' guideline process but it's very difficult and we're not sure of the benefit."

- "Very important but hard to do. Resources are a problem. Need to work out better method. But we are working toward this goal."

- "We think that it is useful to monilor lilerature, we use our broad network of oncological professionals to do so. We see this process as tailored for every guideline, some do not demand frequent updating, others do."

- "As the number of guidelines we have published continues to grow, we are in the early stages of exploring oplions for determining the oplimal frequency for review/update, and the consideration of rapid cycle reviews."

- "Difficult to have a deliberative process if a lot is being updated constantly. Notification of each tpdate would be burdensome for developers and users. Benefit is that information would be much more timely."

- "A forum to discuss and share experiences with different updating procedures would be very welcome!"

Figure 5 Box of relevant comments about future plans for updating guidelines.

\section{Additional material}

Additional file 1: Survey. This document shows the survey designed, based on a literature review about guideline updating.

Additional file 2: Organizations. This document shows information about the organizations that participated in this survey (name, country and source of contact).

\section{Acknowledgements}

The members of the Updating Guidelines Working Group are: Díaz del Campo P, Estrada MD, Gracia J, Mengual J, Rico Iturrioz R, Rotaeche del Campo R, Salcedo-Fernandez F.

We would like to thank the Guideline International Network Secretary, Martina Westermann and Angela Maienborn, for the dissemination of the survey among Guideline International Network members and also to all the key people from all the institutions below that kindly participated in this survey (Agency for Quality in Medicine, American College of Physicians, American Urological Association, American Academy of Otolaryngology, American Academy of Pediatrics, American College of Cardiology, American College of Chest Physicians, American College of Obstetricians and Gynecologists, American College of Radiology, Basque Office for Health Technology Assessment, Belgian Health Care Knowledge Center, Brazilian Medical Association, British Columbia Council on Clinical Practice Guidelines, CARI Guidelines, Catalan Agency for Health Technology Assessment and Research, Current Care/Duodecim-Finnish Medical Society, Domus Medica vzw, Flemish College of General Practitioners, Duodecim Medical Publications Ltd, Dutch Association of Comprehensive Cancer Centres, Dutch Institute for Healthcare Improvement, German Cancer Society e.V., Guidelines Advisory Committee, Health Austria, Federal Institute for Quality in Health Care, HTA Unit, Ministry of Health, Malaysia, Hungarian Ministry of Health, Infectious Diseases Society of America, Italian National Institute of Health, Joanna Briggs Institute, Kidney Disease Improving Global Outcomes, Michigan Quality Improvement Consortium, National Heart Foundation of Australia, National Institute for Clinical Excellence, New Zealand Accident Compensation Corporation, New Zealand Guidelines Group, Registered Nurses Association of Ontario, Royal Dutch Society for Physical Therapy, Scottish Intercollegiate Guidelines Network, Trimbos Institute Netherlands Institute of Mental Health \& Addiction, United States Preventive Services Task Force).

This work has been partially funded within the framework of collaboration of the Quality Plan for the Spanish National Health System, under the terms of the collaboration agreement signed by the Carlos III Health Institute (an autonomous body within the Spanish Ministry for Science and Innovation) 
and the Aragon Health Science Institute, as technical secretariat GuiaSaludBiblioteca project.

Laura Martínez García is a doctoral candidate at the Pediatrics, Obstetrics and Gynecology, and Preventive Medicine Department, Universitat Aunònoma de Barcelona, Barcelona, Spain. Pablo Alonso-Coello is funded by a Miguel Servet research contract from the Instituto de Salud Carlos III (CP09/00137).

\section{Author details}

'Iberoamerican Cochrane Centre, Institute of Biomedical Research (IIB Sant Pau), (C/Sant Antoni Maria Claret 171), Barcelona (08041), Spain. ${ }^{2}$ CIBER of Epidemiology and Public Health (CIBERESP), Barcelona, Spain. ${ }^{3}$ GuíaSaludBiblioteca, Aragon Health Sciences Institute, (Avda. Gómez Laguna 25), Zaragoza, (50009), Spain. ${ }^{4}$ Scottish National Blood Transfusion Service, (21 Ellen's Glen Road), Edinburgh, (EH17 7Q7T), UK. ${ }^{5}$ Dutch College of General Practitioners, (Mercatorlaan 1200), Utrecht, (3528 GL), The Netherlands.

\section{Authors' contributions}

PAC, LMG, JMC, IS, SQ, and JSB participated in the conception and design of the study. LMG, PAC, and JMCG analyzed the data. PAC and LMG drafted a first version. All members of the Updating Guidelines Working Group participated in the design of the study and revising the draft critically for important intellectual content and all authors have given final approval of the version to be published.

\section{Competing interests}

The authors declare that they have no competing interests.

Received: 18 May 2010 Accepted: 13 September 2011

Published: 13 September 2011

\section{References}

1. National Institute for Clinical Excellence: The guidelines manual London: NICE; 2009.

2. Scottish Intercollegiate Guidelines Network: SIGN 50: a guideline developer's handbook Edinburgh: SIGN; 2008.

3. Guyatt GH, Oxman AD, Vist GE, Kunz R, Falck-Ytter Y, Alonso-Coello P, Schünemann HJ, GRADE Working Group: GRADE: an emerging consensus on rating quality of evidence and strength of recommendations. $B M J$ 2008, 336(7650):924-6.

4. Alonso-Coello P, Irfan A, Solà I, Gich I, Delgado-Noguera M, Rigau D, Tort S, Bonfill X, Burgers J, Schunemann H: The quality of clinical practice guidelines over the last two decades: a systematic review of guideline appraisal studies. Qual Saf Health Care 2010, 19(6):e58.

5. Burgers JS, Grol R, Klazinga NS, Makela M, Zaat J: Towards evidence-based clinical practice: an international survey of 18 clinical guideline programs. Int I Qual Health Care 2003, 15(1):31-45.

6. Shekelle PG, Ortiz E, Rhodes S, Morton SC, Eccles MP, Grimshaw JM, Woolf SH: Validity of the Agency for Healthcare Research and Quality clinical practice guidelines: how quickly do guidelines become outdated? JAMA 2001, 286(12):1461-7.

7. Shekelle P, Eccles MP, Grimshaw JM, Woolf SH: When should clinical guidelines be updated? BMJ 2001, 323(7305):155-7.

8. Clark E, Donovan EF, Schoettker P: From outdated to updated, keeping clinical guidelines valid. Int I Qual Health Care 2006, 18(3):165-6.

9. Voisin CE, de I, Whitener L, Gartlehner G: Strategies in assessing the need for updating evidence-based guidelines for six clinical topics: an exploration of two search methodologies. Health Info Libr J 2008, 25(3):198-207.

10. Grupo de trabajo sobre GPC: Elaboración de guías de práctica clínica en el Sistema Nacional de Salud: manual metodológico Madrid: Plan Nacional para el SNS del MSC. Instituto Aragonés de Ciencias de la Salud-I+CS; 2007.

11. Grupo de trabajo sobre implementación de GPC: Implementación de guías de práctica clínica en el Sistema Nacional de Salud: manual metodológico Madrid: Ministerio de Ciencia e Innovación; 2009.

12. Grupo de trabajo sobre actualización de GPC: Actualización de guías de práctica clínica en el Sistema Nacional de Salud: manual metodológico Madrid: Ministerio de Ciencia e Innovación; 2009.

13. New Zealand Guidelines Group: In Living guideline process. Volume 10. N Z Evid Based Health Care Bull; 2010(3).
14. AGREE Collaboration: Development and validation of an international appraisal instrument for assessing the quality of clinical practice guidelines: the AGREE project. Qual Saf Health Care 2003, 12(1):18-23.

15. Schunemann HJ, Woodhead M, Anzueto A, Buist S, Macnee W, Rabe KF, Heffner J: A vision statement on guideline development for respiratory disease: the example of COPD. Lancet 2009, 373(9665):774-9.

16. Fervers B, Remy-Stockinger M, Mazeau-Woynar V, Otter R, Liberati A, Littlejohns P, Qureshi S, Vlayen J, Characiejus D, Corbacho B, Garner S, Hamza-Mohamed F, Hermosilla T, Kersten S, Kulig M, Leshem B, Levine N, Ballini L, Middelton C, Mlika-Cabane N, Paquet L, Podmaniczki E, Ramaekers D, Robinson E, Sanchez E, Philip T, CoCan CPG: Coordination of cancer clinical practice in Europe. Tumori 2008, 94(2):154-9.

17. Fervers B, Burgers JS, Haugh MC, Latreille J, Mlika-Cabanne N, Paquet L, Coulombe M, Poirier M, Burnand B: Adaptation of clinical guidelines: literature review and proposition for a framework and procedure. Int $\mathrm{J}$ Qual Health Care 2006, 18(3):167-76.

18. Mlika-Cabanne N, Harbour R, de Beer H, Laurence M, Cook R, Twaddle S, Guidelines International Network (GIN) Working Group on Evidence Tables: Sharing hard labour: developing a standard template for data summaries in guideline development. BMJ Qual Saf 2011, 20(2):141-5.

doi:10.1186/1748-5908-6-107

Cite this article as: Alonso-Coello et al:: The updating of clinical practice guidelines: insights from an international survey. Implementation Science 2011 6:107.

\section{Submit your next manuscript to BioMed Central and take full advantage of:}

- Convenient online submission

- Thorough peer review

- No space constraints or color figure charges

- Immediate publication on acceptance

- Inclusion in PubMed, CAS, Scopus and Google Scholar

- Research which is freely available for redistribution

Submit your manuscript a www.biomedcentral.com/submit
C Biomed Central 